\title{
Failure Analysis and Research of Key Auxiliaries in Thermal Power Plant
}

\author{
$M A$ Guangyao, ZHANG shuai, MENG Fanyang \\ HUADIAN ELECTRIC POWER RESEARCH INSTITUTE Co., LTD. Turbine and gas turbine technology department , 310030 \\ Hangzhou China
}

\begin{abstract}
The key equipment of thermal power plants such as feed pump ,condensate pump, circulating pump and induced draft fan, blower fan, oxidation fan, air preheater's vibration information are monitored and tracked. Bearing failure accounted for the largest proportion. Problems such as misalignment and unbalance are still very common. Attention should be paid to the fault diagnosis and maintenance work.
\end{abstract}

\section{Introduction}

With the improvement of peaking flexibility of thermal power units the timeliness and stability requirements of equipment response are getting higher and higher. Auxiliary equipment is an important part of the operation system. The stability of auxiliary equipment's operation is also important. The analysis of the operated and fault conditions is carried out after 1600 equipment's management. The faults frequently occurred in the key equipment of the thermal power plant are analyzed.

\section{2 equipment failure statistics}

After classified and managed the auxiliaries of the thermal power plant the key auxiliaries are monitored for vibration and the cause of the auxiliary failures are counted. The key equipment of the thermal power plant are selected including feed water pump ${ }^{[1-3]}$, circulating water pump $p^{[4-5]}$, condensate pump ${ }^{[6-7]}$, induced draft fan ${ }^{[8]}$, blower ${ }^{[9-10]}$, primary fan ${ }^{[11-13]}$, booster fan, oxidation fan ${ }^{[14-16]}$ etc. The operation and the cause of the failure is tracked and studied through a year of time. This study provides a reference for the stable operation and optimization of the key auxiliary equipment of the thermal power plant.

\section{1 pump equipment}

Two hundred and forty-three condensate pumps, two hundred and sixty-eight feed pumps, two hundred and one circulating pumps are monitored. The statistics of the equipment about different failure type numbers can be seen in Figure 1- Figure 3.

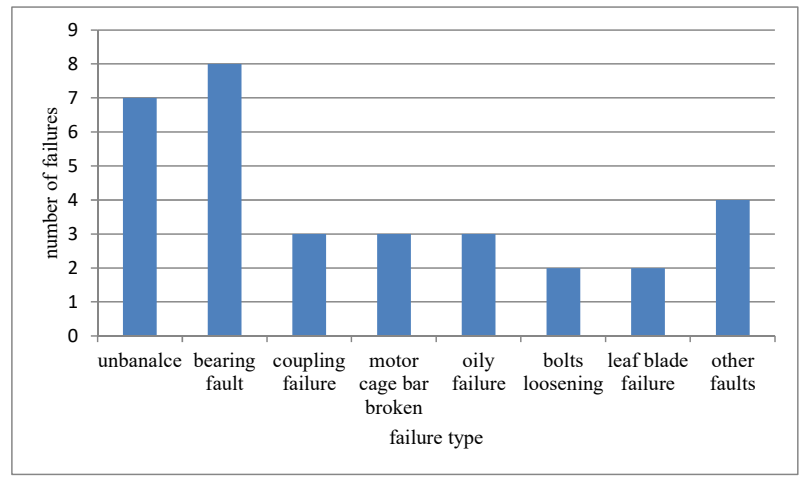

Fig.1. Fault distribution map of feedwater pump

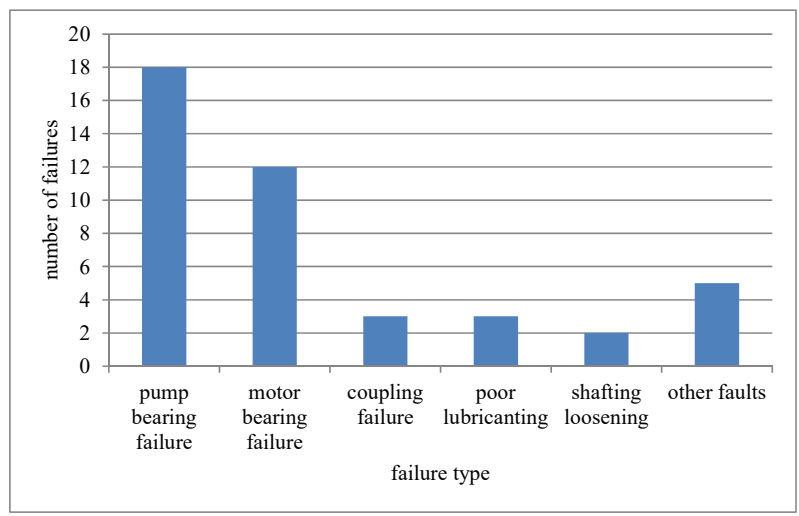

Fig.2. Fault distribution map of water circulating pump 


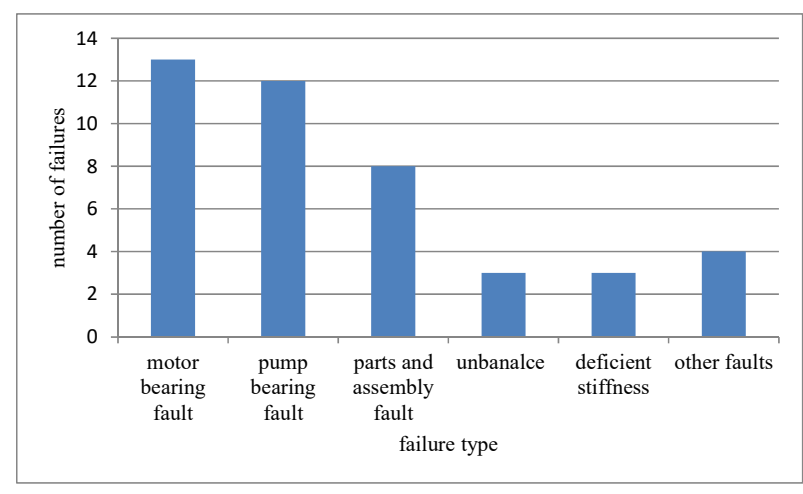

Fig.3. Fault distribution map of condensate pump

In the statistics of all the equipment failure, bearing failure occurred more times. During routine inspection more attention should be paid to the vibration state of the equipment and the lubrication management should be strictly implemented.

\section{2 fan equipment}

Two hundred and thirty-four blower, two hundred and forty-two pilot fan, two hundred and twenty-seven primary fan, two hundred and twenty-six oxidation fan and one hundred booster fan are observed. The vibration monitoring of equipment are carried out. The causes and quantities of equipment failure are shown in Figure 4Figure 10.

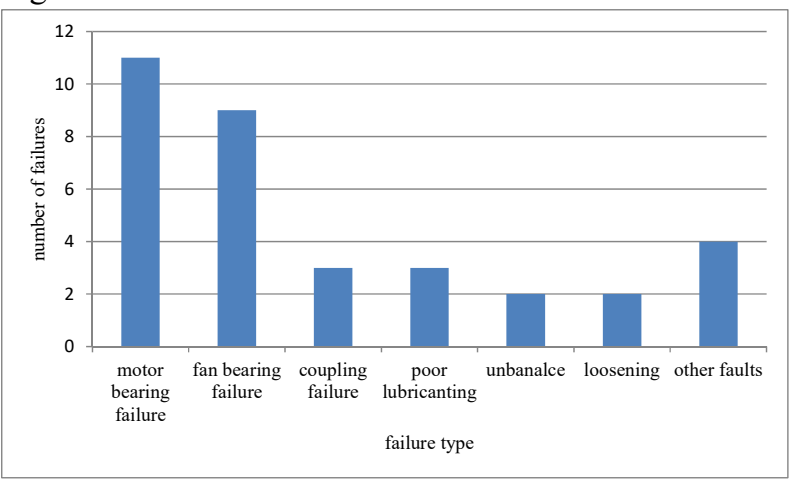

Fig.4. Fault distribution of blower

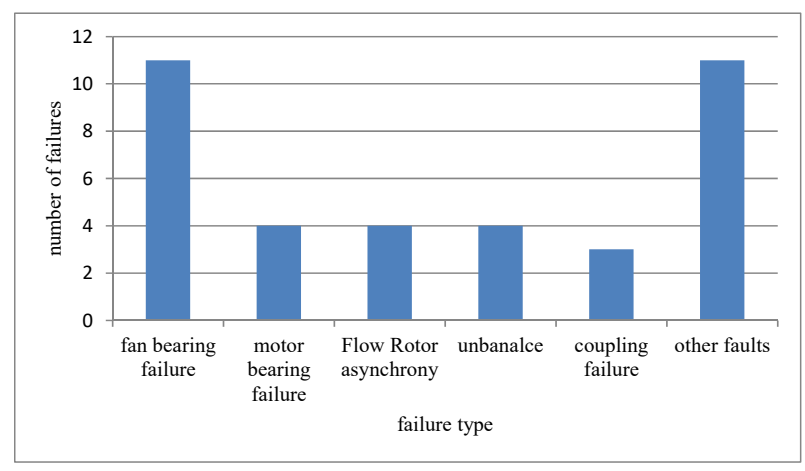

Fig.5. Fault distribution of induced draft fan

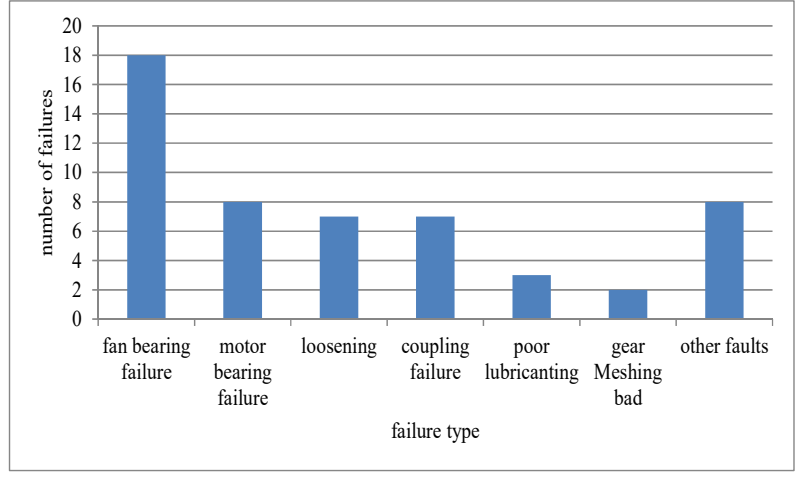

Fig.6. Fault distribution of primary fan

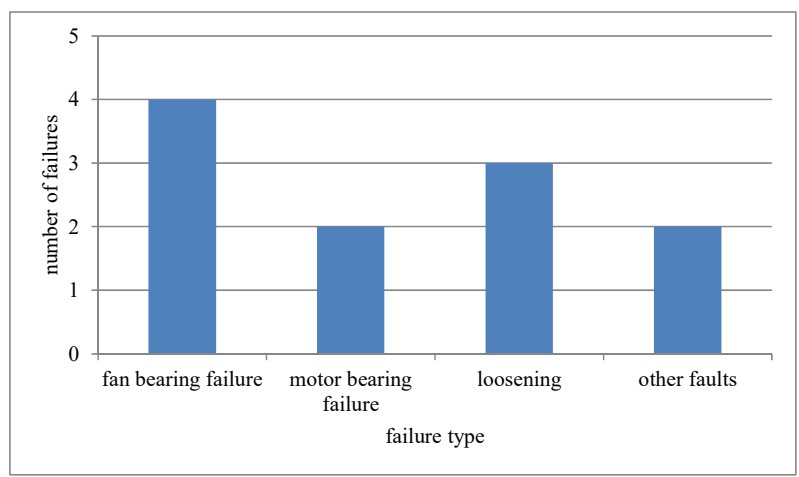

Fig.7. Fault distribution of booster fan

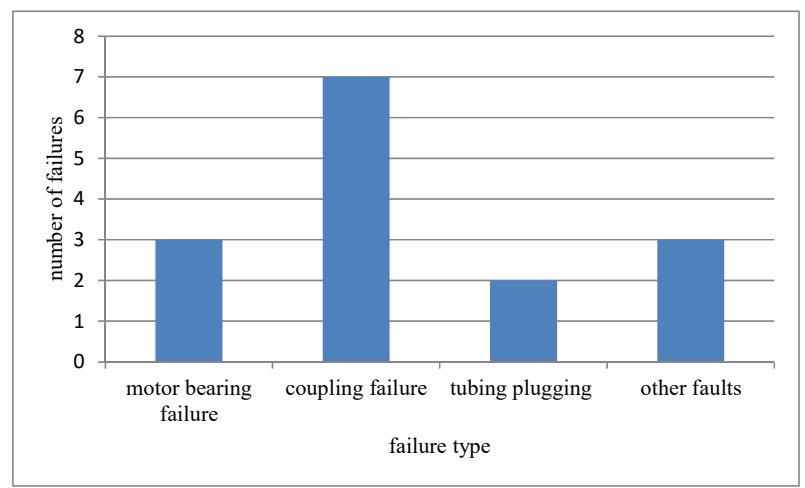

Fig.8. Fault distribution of air preheater

According to the statistics it can be seen that the bearing component has the highest failure rate. The unbalanced faults are very common. Misalignment of the equipment during installation and the looseness of the components are still one of the main causes of failure. According to statistics the equipment failure rate is generally between $10 \%$ to $25 \%$ ( shown in Figure 9 ). The failure rate of primary fan and circulating water pump are higher than 20\%. Monitoring and maintenance should be strengthened during subsequent operations. 


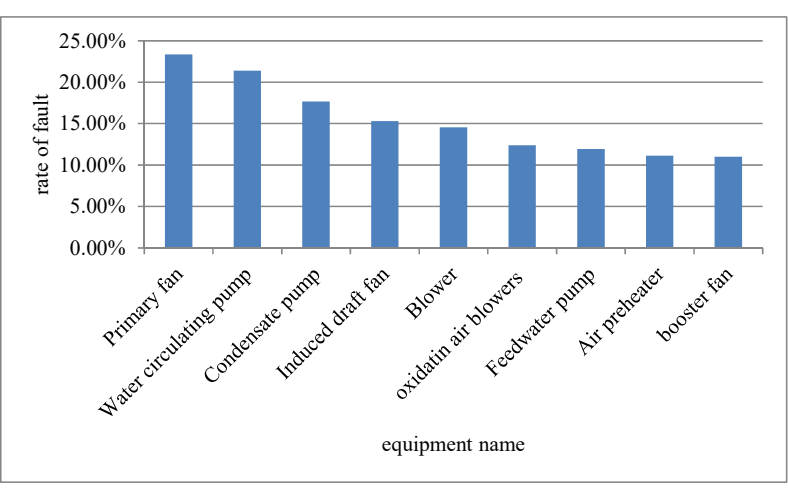

Fig.9. Rate of fault about different equipment

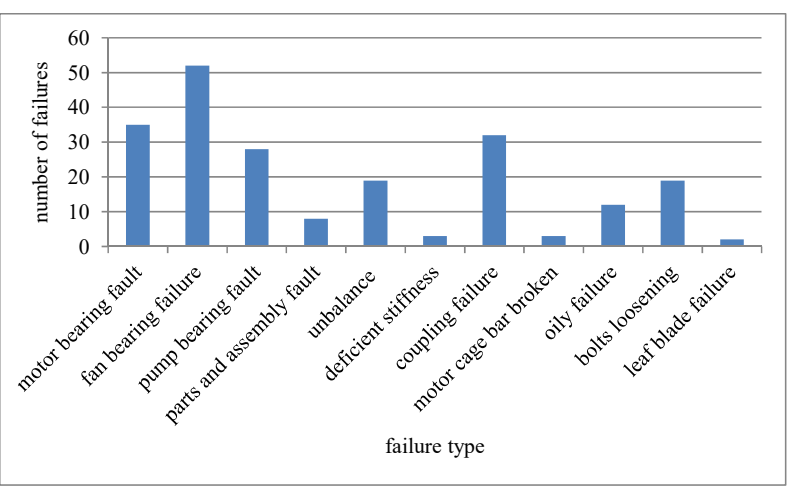

Fig.10. Numbers about different failure type

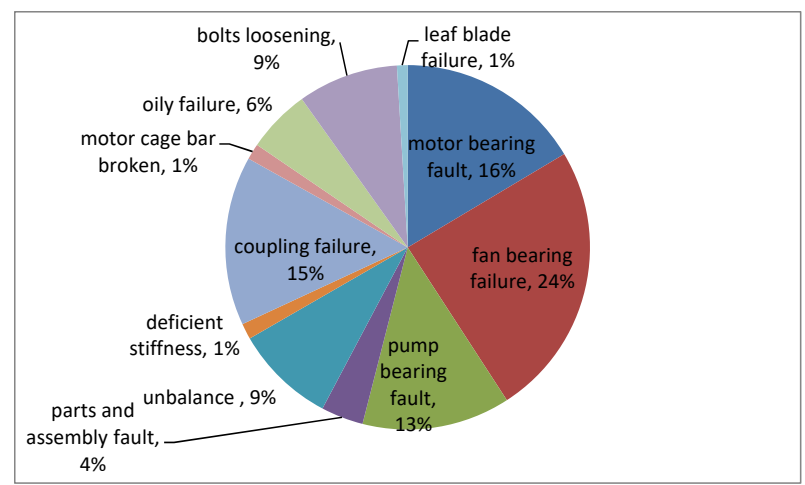

Fig.11. Different fault ratio analysis

As can be seen from the figure above, bearing faults occur most frequently, and non-neutralization and loosening faults account for a large proportion

\section{Equipment fault diagnosis and unit operation analysis}

In recent years, there have been many researches on auxiliary engine faults in thermal power plants. The key auxiliary equipment that caused the unit shutdown are counted during the past five years. The results are shown in Table 1.
Table 1 Statistics on equipment of unit shutdown in the past five years

\begin{tabular}{|c|c|r|l|}
\hline year & \multicolumn{3}{|c|}{ Faulty device name } \\
\hline 2014 & Feed pump & Air preheater & Booster fan \\
\hline 2015 & Feed pump & $\begin{array}{r}\text { Induced } \\
\text { draft fan }\end{array}$ & Air preheater \\
\hline 2016 & $\begin{array}{c}\text { Induced draft } \\
\text { fan }\end{array}$ & Feed pump & Air preheater \\
\hline 2017 & Feed pump & Booster fan & Primary Fan \\
\hline 2018 & Booster fan & Primary Fan & Feed pump \\
\hline
\end{tabular}

According to the unit shutdown statistics caused by major equipment from 2014 to 2018 it presents a downward trend year by year as shown in Figure 12.

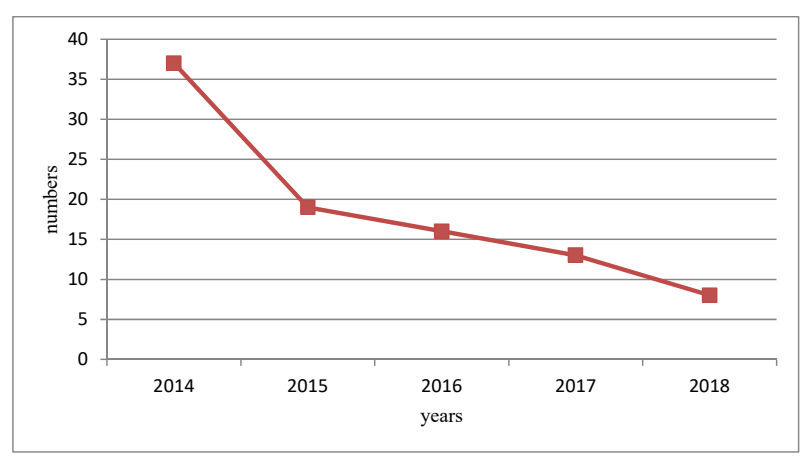

Fig.12. Precision inspection of the unit shutdown accidents caused by main auxiliary equipment

\section{Conclusion}

Among the unit shutdown accidents of the auxiliary equipment the failure of the auxiliaries is one of the main reason. The failure mainly concentrated in the feed water pump, air preheater, booster fan, primary fan, induced draft fan. The fault manifestation mainly depended on vibration. The statistical analysis of the failure of the key auxiliaries is done. The failure of the key auxiliaries are understood. The outage and derated of the unit is effectively avoided.. Effectively avoiding unit shutdown accidents and lowering forces. Strengthening the monitoring of specific equipment and components based on normal monitoring can reveal problems of auxiliaries. From the statistical data the trend of declining year by year it should be emphasized. Each power plant can attached great importance through precision inspection. Strengthen the auxiliaries management can be used to reduce and avoid the occurrence of unit shutdown accidents.

\section{References}

1. DONG HQ. Cause Analysis and Solution of Vibration Fault of Motor-driven Feed Water Pump for Coal-fired Unit[J]. Power Generation Tech. Vol.40 No.3(2019).1-5. 
2. XUE DQ. Analysis of the Causes of Water Feed Pump Vibration and Countermeasures[J]. Metallurgical Power. Vol.4 (2019).36-39.

3. ZHANG FH, ZHOU ZP, SUN ZZ, ZHU J, ZHAO D. Analysis on Vibration Cause of Nuclear Power Fixed-speed Main Feed Pump with Elastic Foundation[J]. Electric Engineering. Vol.8(2019).107-112.

4. WANG HQ. Cause Analysis and Treatment of Circulating Pump Vibration in 350 MW Unit[J]. Modern Industrial Economy and Informationization. Vol.176 (2019)133-135.

5. XU S. Application of Precise Inspection in the Circulating Pump Fault Diagnosis[J]. Power Station Auxiliary. Vol.39. No.1 (2018).39-42.

6. LI W. Analysis and treatment of vertical multi stage condensate pump vibration[J]. Equipment Technology. Vol.170.(2019). 160-161.

7. CHEN Y. Comparison on Two Dynamic Balancing Schemes of Condensate Pump in a Power Plant[J]. Thermal Turbine. Vol.47. (2018):212-220.

8. ZHANG HT, CHANG Q, WU J, XUE YF. Analysis and Treatment of Vibration Faults for 600MW Unit Static Blade Adjustable Steam Driven Induced Draft Fan[J]. Power System Engineering. Vol.35. (2019). 55-57.

9. MA XY. Vibration analysis of multi - stage blower in operation[J]. Shandong Industrial Technology. Vol.38(2018):11-12.

10. LUO WH. Discussion on vibration cause of multi stage blower in operation[J]. Technology and Economic Guide Vol.27. (2019). 103.

11. ZHAO YJ, TIAN S. Diagnosis and Treatment of Anomaly Vibration of Rolling Bearing on Primary Fan for $330 \mathrm{MW}$ Boiler[J]. Inner Mongolia Electric Power. Vol 8.(2019):10-14.

12. ZHANG YJ. Analysis of Primary Fan Bearing Deterioration Based on Vibration Theory[J].Shanxi Electric Power.Vol.214.(2019):66-68.

13. WANG PB. Treatment of large vibration of primary fan in xiangyang power plant of hubei province[J]. Huadian Technology. Vol.39. (2017):58-59.

14. DU Y. Analysis on the cause and treatment of large vibration of desulfurization oxidation fan[J]. Electrical Information. Vol. Vol.360 .(2013). 37-38.

15. SUN MC, ZHANG YX. Reasons Analysis on Fracture of a Desulfurization and Oxidation Fan Shaft[J]. Physical Testing and Chemical Analysis. Vol.50.(2014).929-932.

16. WANG JQ. Failure Analysis and Preventive Measures for Fracture of Oxidation Fan Shaft[J]. Journal of Anhui Electrical Engineering Professional Technique College. Vol.20 (2015).61-64. 